\title{
A agroindústria canavieira no Paraná e seus aspectos locacionais: uma abordagem sobre o zoneamento agroecológico da cana-de-açúcar
}

\author{
Pery Francisco Assis Shikida*
}

\begin{abstract}
RESUMO - Este estudo tem como objetivo contextualizar o decréscimo da importância relativa da agroindústria canavieira paranaense a partir de apontamentos sobre o zoneamento agroecológico da cana-de-açúcar (ZAE Cana). Dentre os cinco principais produtores de cana do Brasil (SP, MG, GO, PR e MS), dados da safra 2010/2011, o Paraná é o que tem o menor potencial de área antropizada apta para a expansão de plantio. O ZAE Cana vem fornecendo subsídios para o planejamento de futuros polos de desenvolvimento canavieiro no espaço rural, indicando a espacialização de áreas aptas à expansão dessa cultura, que somadas às razões de migração da produção canavieira para novas fronteiras, fazem com que a agroindústria canavieira paranaense, por esta ótica, apresente a menor vantagem comparativa para uma expansão horizontal vis-à-vis estados como GO, MG e MS.
\end{abstract}

Palavras-chave: ZAE Cana. Expansão. Paraná.

\section{INTRODUÇÃO}

Conforme Neves et al. (2010, p. 16-17), a agroindústria canavieira movimentou, em 2008, uma "riqueza de US\$28,15 bilhões, equivalente a quase $2 \%$ do Produto Interno Bruto do Brasil. [...] O setor mantém 1,28 milhão de postos de trabalho formais [...], e a massa salarial é estimada em US\$738 milhões”. Com estas cifras, este segmento, de importância histórica - a ponto de ter propiciado o ciclo do açúcar (entre 1530 a 1650, período fundamentado basicamente nas exportações de açúcar) -, mantém sua posição como um dos mais importantes segmentos do agronegócio nacional no século XXI. A magnitude econômica da agroindústria canavieira pode ser retratada por alguns indicadores. O Brasil é o maior produtor mundial de cana-de-açúcar, seguido por Índia, China e Tailândia. Na safra 2010/2011 foram colhidas em terras brasileiras 624 milhões de toneladas de cana, sendo produzidas 38,2 milhões de toneladas de açúcar (maior produtor mundial) e 27,6 milhões de $\mathrm{m}^{3}$ de álcool (segundo maior produtor mundial, perdendo para os Estados Unidos). A cultura canavieira ocupa cerca de 8,4 milhões de hectares, aproximadamente 2,4\% de toda a terra arável do país (São Paulo detém 54\% dessa área, seguido por Minas Gerais, 8\%, Paraná, 7,5\%, Goiás, 7,4\% e Alagoas, 5,7\%), e devido às

\footnotetext{
* Doutor em Economia Aplicada pela Escola Superior de Agricultura Luiz de Queiroz/Universidade de São Paulo. Pós-Doutor pela Fundação Getúlio Vargas/SP. É professor associado da Universidade do Oeste do Paraná, bolsista produtividade em pesquisa do CNPq e professor do Programa de Mestrado em Economia Regional da Universidade Estadual de Londrina. Endereço eletrônico: peryshikida@hotmail.com.
} 
regiões de cultivo ocuparem tanto áreas do norte-nordeste como do centro-sul, permitem-se duas safras por ano. O Brasil também é o maior exportador sucroalcooleiro do mundo, tendo exportado 28 milhões de toneladas de açúcar em 2010, o que gerou uma receita de aproximadamente 13 bilhões de dólares, e quase 2 bilhões de litros de álcool etílico, o que gerou uma receita de 1 bilhão de dólares. Além disso, os veículos flexfuel, que possibilitam tanto o uso de gasolina como de álcool, ou de um mix entre ambos, representam um fator de suma importância para dinamização da agroindústria alcooleira nacional (a produção de álcool quase dobrou entre a safra 2003/2004 - quando este tipo de veículo foi lançado no mercado automotivo - e a safra 2010/2011). A participação de veículos flexfuel no total do mercado brasileiro de veículos leves é de 83,6\% (os dados deste parágrafo foram compilados da União da Agroindústria Canavieira de São Paulo - UNICA (2011); Associação de Produtores de Bioenergia do Estado do Paraná - ALCOPAR (2011); Organização das Nações Unidas para Agricultura e Alimentação - FAO (2009); e Ministério do Desenvolvimento, Indústria e Comércio Exterior - MDIC (2011)).

O estado do Paraná, de acordo com os dados da última safra (2010/2011), é o quarto maior produtor de cana-de-açúcar nacional, mas já figurou na segunda posição até bem pouco tempo atrás (SHIKIDA, 2010). Sua localização geográfica estratégica é uma fonte de vantagens competitivas para a agroindústria canavieira, sendo que quase $100 \%$ da cana-de-açúcar produzida no Paraná se concentra no norte do estado (acima do Paralelo 24), que detém terras aptas ao cultivo (de excelentes condições edafoclimáticas), com disponibilidade de mão de obra, facilidade de transporte da produção e proximidade com o mercado consumidor centro-sulista, e onde o movimento de expansão se apresenta com maior ímpeto. Ademais, em termos de vantagens específicas do setor, o Paraná possui um qualificado parque industrial de processamento de cana para a fabricação de açúcar e/ou álcool, que já soma 30 unidades produtoras, com impacto econômico sobre 142 municípios (SOUZA et al., 2005; TSCHÁ et al., 2010; ALCOPAR, 2011).

Isto posto, este conciso estudo tem como escopo contextualizar o decréscimo de importância relativa da agroindústria canavieira paranaense (por alguns anos figurou como o segundo maior produtor nacional) a partir de um item, mais recente neste meio, de vantagem (ou desvantagem) locacional que pretende disciplinar a expansão da cana-de-açúcar em todo o Brasil, qual seja, o zoneamento agroecológico da cana-de-açúcar (ZAE Cana).

\section{UMA ABORDAGEM SOBRE O ZONEAMENTO AGROECOLÓGICO DA CANA- DE-AÇÚCAR NO PARANÁ}

Antes de expor uma abordagem do ZAE Cana, cumpre discutir alguns aspectos da 
Tabela 1, a seguir, onde se verificam algumas transformações pelas quais passam a economia canavieira. Em termos de participação percentual média da produção de cana-de-açúcar no total produzido no Brasil (dados das safras 1990/1991 a 2010/2011), observa-se que São Paulo $(60,61 \%)$ é o principal representante nacional neste quesito, seguido, de longe, por Alagoas (7,17\%), Paraná (7,09\%), Pernambuco (5,22\%), Minas Gerais (5,21\%), Goiás (3,39\%), Mato Grosso (2,78\%) e Mato Grosso do Sul (2,47\%) (esses estados foram responsáveis por 93,94\% do total produzido no país de cana-de-açúcar no período em epígrafe).

TABELA 1 - PARTICIPAÇÃO \% MÉDIA DA PRODUÇÃO DE CANA-DE-AÇÚCAR DOS PRINCIPAIS ESTADOS PRODUTORES NO TOTAL PRODUZIDO NO BRASIL E TAXA DE CRESCIMENTO ANUAL MÉDIO DA PRODUÇÃO DE CANA-DE-AÇÚCAR (1990/1991 A 2010/2011)

\begin{tabular}{l|r|r|r}
\hline \multicolumn{1}{c|}{ Estados } & $\begin{array}{c}\text { Participação \% média da } \\
\text { produção de cana-de-açú- } \\
\text { car no total produzido no } \\
\text { Brasil (dados das safras } \\
\mathbf{1 9 9 0 / 1 9 9 1 ~ a ~ 2 0 1 0 / 2 0 1 1 )}\end{array}$ & $\begin{array}{c}\text { Participação \% média da } \\
\text { produção de cana-de-açú- } \\
\text { car no total produzido no } \\
\text { Brasil (dados para o triênio } \\
\text { das safras 2008/2009 a } \\
\mathbf{2 0 1 0 / 2 0 1 1 )}\end{array}$ & $\begin{array}{c}\text { Taxa de crescimento } \\
\text { anual médio da produção } \\
\text { de cana-de-açúcar (safra } \\
\mathbf{1 9 9 0 / 1 9 9 1 ~ a ~ 2 0 1 0 / 2 0 1 1 ) ~}\end{array}$ \\
\hline São Paulo & 60,61 & 59,66 & $5,1 \%$ \\
Minas Gerais & 5,21 & 8,24 & $9,6 \%$ \\
Paraná & 7,09 & 7,46 & $7,0 \%$ \\
Goiás & 3,39 & 6,41 & $11,2 \%$ \\
Alagoas & 7,17 & 4,49 & $1,8 \%$ \\
Mato G. do Sul & 2,47 & 4,14 & $10,1 \%$ \\
Pernambuco & 5,22 & 3,02 & $0,1 \%$ \\
Mato Grosso & 2,78 & 2,40 & $8,6 \%$ \\
Paraíba & 1,35 & 0,97 & $2,6 \%$ \\
Espírito Santo & 0,76 & 0,67 & $5,9 \%$ \\
Rio de Janeiro & 1,51 & 0,55 & $-2,5 \%$ \\
Rio G. do Norte & 0,74 & 0,53 & $1,9 \%$ \\
Bahia & 0,62 & 0,41 & $3,5 \%$ \\
Maranhão & 0,30 & 0,38 & $11,3 \%$ \\
Sergipe & 0,36 & 0,30 & $4,2 \%$ \\
Piauí & 0,13 & 0,15 & $4,8 \%$ \\
Ceará & 0,07 & 0,02 & $-12,4 \%$ \\
Brasil & --- & -- & $5,3 \%$ \\
\hline
\end{tabular}

FONTE: Compilado de UNICA (2011) e ALCOPAR (2011).

NOTA: 1 A estimativa da taxa geométrica de crescimento, calculada para todo o período, está de acordo com o método dos mínimos quadrados. Maiores considerações, ver Hoffmann e Vieira (1987).

Contudo, verificando uma tendência relativa mais atual, a contar pela participação percentual média da produção de cana-de-açúcar no total produzido no Brasil, dados apenas para o último triênio verificado (safra 2008/2009 a 2010/2011), constatar-se-á que os estados supracitados foram responsáveis, desta vez, por 95,82\% do total produzido, ou seja, houve uma concentração espacial ainda maior da produção neste conjunto de estados. Porém, dentre estes principais produtores houve diferenças evolutivas. Neste sentido, nota-se uma mudança espacial referente à elevação da representatividade de regiões onde o cultivo canavieiro não era destaque 
secular, como, por exemplo, em Minas Gerais (que passa a ser o segundo representante nacional neste quesito), Goiás e Mato Grosso do Sul. Ao contrário, em Pernambuco e Alagoas, estados tradicionais neste segmento produtivo, se verificam as mais acentuadas quedas em termos de importância relativa, isto dentre os oito principais estados produtores de cana-de-açúcar.

Quando se verifica a taxa de crescimento anual média da produção de cana-de-açúcar (safra 1990/1991 a 2010/2011), corrobora-se que Goiás (11,2\%), Mato Grosso do Sul (10,1\%) e Minas Gerais (9,6\%) foram destaques também neste contexto. Em seguida aparece outra fronteira de importância para a economia canavieira, o estado do Mato Grosso (8,6\%); Alagoas e Pernambuco confirmaram suas quedas relativas com taxas de crescimento pouco expressivas. Ademais, embora estejam com participações percentuais médias no total produzido de cana abaixo da casa de um dígito $(0,30 \%$ e $0,76 \%$, respectivamente), vale ressaltar que os estados do Maranhão e Espírito Santo alcançaram crescimentos significativos (11,3\% e 5,9\%, respectivamente). São Paulo, mesmo diante dessas incursões, cresceu 5,1\%.

Ora, por que tais vicissitudes de alteração geográfica ocorreram e estão ocorrendo? Várias razões são expostas pela literatura, como: a elevação dos custos da terra; a relativa saturação das áreas disponíveis em regiões tradicionalmente produtoras; benefícios fiscais, sobretudo em novas fronteiras; desregulamentação; as áreas contíguas às tradicionais regiões produtoras de cana apresentam atrativos edafoclimáticos que permitem desenvolver sistemas produtivos similares aos existentes em regiões tradicionais, que levam inclusive o conhecimento, as experiências técnicas-comerciais e o aparato tecnológico moderno para as novas áreas etc. (SHIKIDA, 1997; CARRIJO; MIZIARA, 2009; BNDES; CGEE, 2008).

De acordo com Fernandes et al:

Esta recente alteração geográfica está associada com a migração da produção sucroalcooleira nacional, antes concentrada no estado de São Paulo [...] e faixa litorânea nordestina, e que com a desregulamentação setorial (pós-anos 1990) favoreceu a entrada nesse mercado de outros estados até então sem expressão na agroindústria da cana-de-açúcar - foi o caso do Paraná, Mato Grosso do Sul e Goiás - , mas com condições econômicas e edafoclimáticas substanciais para atrair o capital canavieiro. (FERNANDES et al., 2011, p. 08).

Conforme estudos do Instituto de Pesquisa Econômica Aplicada - IPEA (2010) e Shikida (2010), o crescimento das exportações brasileiras de açúcar, a nova dinâmica do mercado alcooleiro - com a introdução do veículo flexfuel no Brasil e com o estímulo ao uso de fontes de energia renovável - , e o mercado interno em expansão, explicam boa parte do aumento do mercado sucroalcooleiro nacional nos últimos anos. Não obstante, vale frisar o que Fernandes 
et al. (2011) bem colocam, isto é, os motivos que levam uma determinada região a apresentar melhores resultados em termos de criação de novas unidades produtoras e consequente geração de postos de trabalho do que outras se devem à sua estrutura produtiva eficiente, por ter vantagens competitivas e especialização, ou porque tal cultura tem produzido commodities que estão entre as mais comercializadas em nível mundial.

Entretanto, nesta discussão, uma nova variável, importante na expansão da cultura canavieira por ser capaz de induzir à limitação de algumas áreas e tornar favoráveis outras, é o zoneamento agroecológico da cana-de-açúcar (ZAE Cana), que pretende disciplinar a expansão da produção de cana-de-açúcar em todo o Brasil.

As áreas indicadas para a expansão pelo zoneamento agroecológico da cana compreendem aquelas atualmente em produção agrícola intensiva, produção agrícola semi-intensiva, lavouras especiais (perenes, anuais) e pastagens. Estas foram classificadas em três classes de potencial (alto, médio e baixo) discriminadas ainda por tipo de uso atual predominante (Agropecuária, Agricultura e Pastagem). [...] Estas estimativas demonstram que o país não necessita incorporar áreas novas e com cobertura nativa ao processo produtivo, podendo expandir ainda a área de cultivo com cana-de-açúcar sem afetar diretamente as terras utilizadas para a produção de alimentos. [...] Unidades industriais já instaladas, a produção de cana para seu suprimento e a expansão programada não são objeto deste zoneamento (MANZATTO et al., 2009, p. 7, 9).

A Tabela 2 apresenta um quadro da área antropizada (há ocupação do homem, ou alterada pela ação do homem, incluindo não só cultivo, mas pastos e demais usos) apta para a expansão do plantio da cana-de-açúcar para os principais estados produtores. Nesta tabela percebe-se que a maior extensão de terras aptas está de fato nos estados onde a dinâmica recente da produção canavieira vem ocorrendo com mais veemência, mormente em Goiás, Minas Gerais e Mato Grosso do Sul. Ao revés, Alagoas e Pernambuco apresentam as menores áreas antropizadas aptas para a expansão do plantio de cana-de-açúcar.

TABELA 2 - ZAE CANA PARA OS PRINCIPAIS ESTADOS PRODUTORES NO BRASIL

\begin{tabular}{l|r|r}
\multicolumn{1}{c}{ Estados } & $\begin{array}{c}\text { Área total do estado } \\
\text { (hectares) }\end{array}$ & $\begin{array}{c}\text { Área antropizada apta para a expansão do } \\
\text { plantio - ZAE Cana (hectares) }\end{array}$ \\
\hline Goiás & 34.008 .669 & 12.600 .530 \\
Minas Gerais & 58.652 .829 & 11.250 .202 \\
Mato Grosso do Sul & 35.712 .496 & 10.869 .820 \\
São Paulo & 24.820 .942 & 10.645 .484 \\
Mato Grosso & 90.335 .790 & 6.812 .854 \\
Paraná & 19.931 .485 & 4.039 .496 \\
Maranhão & 33.198 .329 & 789.547 \\
Alagoas & 2.776 .766 & 450.537 \\
Pernambuco & 9.831 .161 & 205.157 \\
\hline
\end{tabular}

FONTE: Manzatto et al. (2009). 
A Figura 1 perscruta melhor o retrato do ZAE Cana para o Paraná. De acordo com este zoneamento há: 2.644 mil hectares considerados de aptidão agrícola alta; 800 mil hectares considerados de aptidão agrícola média; e 595 mil hectares considerados de aptidão agrícola baixa, ambos considerando o somatório do uso atual com pastagens, agropecuária e agricultura. Vale citar que a área com cana em terras paranaenses já perfaz aproximadamente 630 mil hectares.

FIGURA 1 - ZAE CANA PARA O ESTADO DO PARANÁ

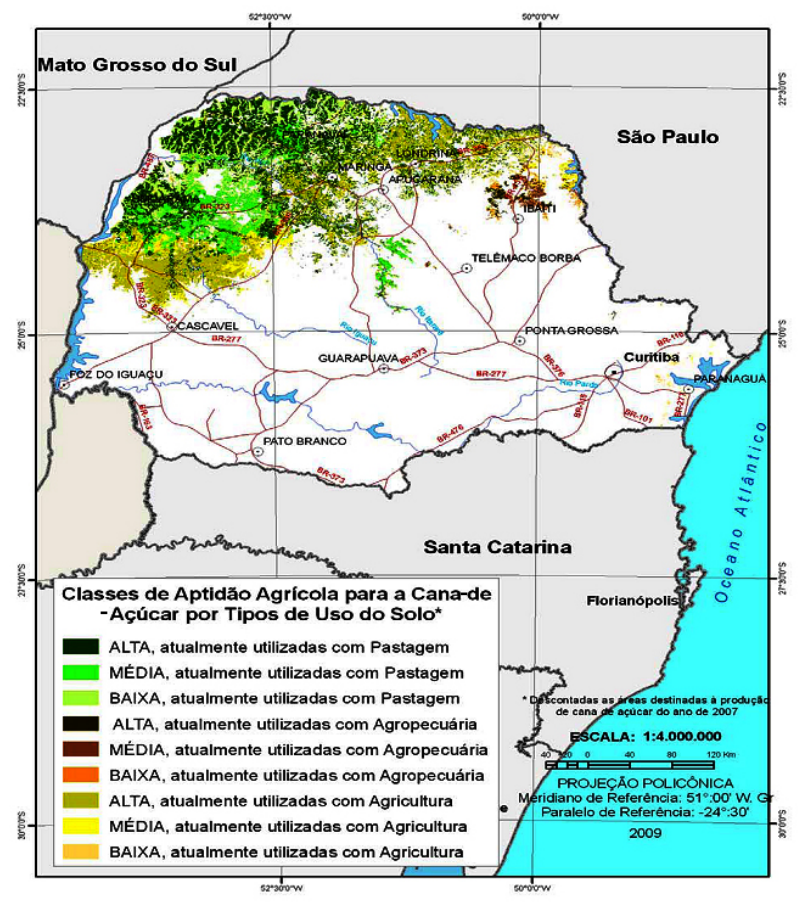

FONTE: Manzatto et al. (2009).

Com efeito, este zoneamento agroecológico está contribuindo não só para disciplinar a expansão da produção de cana-de-açúcar em território nacional, como também vem fornecendo subsídios para o planejamento de futuros polos de desenvolvimento canavieiro no espaço rural, indicando a espacialização de áreas aptas à expansão do cultivo de cana (MANZATTO et al., 2009) que, somadas às razões de migração da produção canavieira para novas fronteiras, fazem com que a agroindústria canavieira paranaense, por esta ótica, apresente a menor vantagem comparativa para expansão horizontal vis-à-vis estados como Goiás, Minas Gerais e Mato Grosso do Sul. Ou seja, dado o fim da fronteira agrícola (compreendida como a expansão do processo de ocupação do solo em áreas que não tinham determinada aptidão agropecuária (CARRIJO; MIZIARA, 2009)) no Paraná, e considerando seu tamanho físico relativamente menor (vide Tabela 2), a expansão de qualquer atividade agropecuária neste estado somente se dará mediante substituição de outros usos agropecuários, que ainda assim têm restrições. 


\section{CONSIDERAÇÕES FINAIS}

Este estudo teve como objetivo contextualizar o decréscimo de importância relativa da agroindústria canavieira paranaense a partir de apontamentos sobre o ZAE Cana, que sinaliza para uma vantagem (ou desvantagem) locacional geográfica.

Dentre os cinco principais produtores de cana-de-açúcar do Brasil, safra 2010/2011 (SP, MG, GO, PR e MS), o Paraná é o que possui a maior restrição física em termos de área total e de área antropizada apta para a expansão do plantio de cana. Tal apontamento interfere de alguma forma nas expectativas de investimento e crescimento da produção sucroalcooleira paranaense. Afora isto, ainda existem novas fronteiras com custos e aptidões também favoráveis à agroindustrialização da cana (como elevada disponibilidade de áreas, recursos hídricos abundantes, clima e topografia favorável, benefícios fiscais etc.). A concatenação destes dois argumentos evidencia que o cenário atual e futuro para o estado do Paraná é de perda de importância relativa na economia canavieira, dessa vez em face de sua desvantagem locacional geográfica dada pela limitação espacial de expansão horizontal. Mesmo assim, sua localização geográfica continua sendo fonte de vantagens competitivas para a agroindústria canavieira, derivadas de terras aptas ao cultivo, disponibilidade de mão de obra, facilidade logística e proximidade física com o dinâmico mercado consumidor centro-sulista.

Diante do exposto, percebe-se que a agroindústria canavieira paranaense vem passando por importantes mudanças. Há, evidentemente, fatores limitantes e potenciais nessas mudanças que podem e devem ser melhor avaliados. Destarte, como agenda de pesquisa, sugere-se que mais estudos possam ser implementados para examinar novas contextualizações (sobre este setor) em níveis que este trabalho não possibilitou conclusões.

\section{REFERÊNCIAS}

ALCOPAR. Estatísticas 2011. Disponível em: < http://www.alcopar.org.br/estatisticas/hist_ prod_br.php>. Acesso em: 1/7/2011.

BNDES; CGEE (Org.). Bioetanol de cana-de-açúcar: energia para o desenvolvimento sustentável. Rio de Janeiro: BNDES, 2008. 316 p.

CARRIJO, E. L. O.; MIZIARA, F. A expansão do setor sucroalcooleiro como uma nova etapa da fronteira agrícola em Goiás: estudo de caso no município de mineiros. Revista de Economia da UEG. Anápolis, v. 5, n. 2, p. 92-121, jul./dez. 2009.

FAO. Countries by commodity - sugar cane. 2009. Disponível em: < http://faostat.fao.org/ site/339/default.aspx>. Acesso em: 1/7/2011.

FERNANDES, C. B. S.; SHIKIDA, P. F. A.; CUNHA, M. S. O mercado de trabalho formal no setor sucroalcooleiro no Brasil. In: CONGRESSO DA SOBER, 49., Belo Horizonte. Anais... Belo Horizonte: SOBER/UFMG, 2011. 
HOFFMANN, R; VIEIRA, S. Análise de regressão: uma introdução à econometria. 2. ed. São Paulo: HUCITEC, 1987. 379 p.

IPEA. Biocombustíveis no Brasil: etanol e biodiesel - Série Eixos do Desenvolvimento Brasileiro. Rio de Janeiro: IPEA, 2010.

MANZATTO, C. V.; ASSAD, E. F.; BACCA, J. F. M.; ZARONI, M. J.; PEREIRA, S. E. M. Zoneamento agroecológico da cana-de-açúcar. Rio de Janeiro: Embrapa Solos, 2009. 55 p.

MDIC. Álcool combustível 2011. Disponível em: < http://www.mdic.gov.br/sitio/interna/interna.php?area $=2 \&$ menu=999>. Acesso em: $1 / 7 / 2011$.

NEVES, M. F.; TROMBIN, V. G.; CONSOLI, M. O mapa sucroenergético do Brasil. SOUZA, E. L. de; MACEDO, I. de C. (Coord.). Etanol e bioeletricidade: a cana-de-açúcar no futuro da matriz energética. São Paulo: Luc Projetos de Comunicação, 2010. p. 14-43.

SHIKIDA, P. F. A. A evolução diferenciada da agroindústria canavieira no Brasil de 1975 a 1995. 191 p. Tese (Doutorado) - Escola Superior de Agricultura Luiz de Queiroz - Universidade de São Paulo, Piracicaba, 1997.

SHIKIDA, P. F. A. Desenvolvimento socioeconômico e agroindústria canavieira no Paraná. Revista de Política Agrícola, Brasília, ano XIX, n. 3, p. 67-82, jul./set. 2010.

SOUZA, E. C. de; SHIKIDA, P. F. A.; MARTINS, J. P. Uma análise da agroindústria canavieira do Paraná à guisa da matriz de capacidades tecnológicas. Revista de Economia e Agronegócio, Viçosa, v. 3, n. 3, p. 349-375, jul./set. 2005.

TSCHÁ, O. da C. P.; TOMASETTO, M. Z. de C.; SHIKIDA, P. F. A.; ALVES, L. R.; BUENO, R. Encadeamento produtivo, localização e associação geográfica da agroindústria canavieira no Paraná. Redes, Santa Cruz do Sul, v. 15, n. 1, p. 128-155, jan./abr. 2010.

UNICA. Dados e cotações 2011. Disponível em: <www.unica.com.br>. Acesso em: $12 / 7 / 2011$. 